\title{
Reviews spark debate over breast screening
}

\section{Jonathan Knight, San Francisco}

Faced with intense disagreement among epidemiologists over the best way to measure the health benefits of mammograms, the United States may be preparing to edge away from its long-standing policy of officially encouraging their use.

A review by the Copenhagen-based Nordic Cochrane Centre, published last October, questioned some of the studies cited to justify the use of mammography (see Lancet 358, 1340-1342; 2001). In response to this, the US National Cancer Institute (NCI) now says it may revisit its current recommendation that all women over the age of 40 should receive regular mammograms.

And as public doubts grow over the robustness of the evidence on which the recommendation is based, two senators with strong influence over health policy, Barbara Mikulski (Democrat, Maryland) and Tom Harkin (Democrat, Iowa), have pledged to hold committee hearings on the topic in the next few weeks.

The dispute about the evidence centres on which data epidemiologists should measure when they study the outcome of cancer screening. If they measure cancer deaths only, the screening appears beneficial, some studies suggest. But if they measure overall mortality — including deaths that may result from intrusive cancer treatments, such as chemotherapy and surgery - the outcome becomes far murkier.

This week, researchers who believe that mammograms save lives hit back at the Cochrane review, arguing in the current issue of The Lancet (see Lancet 359, 404-406; 2002) that its methods served to bury real, statistically significant evidence of health benefits from mammograms.

The authors of the new review, led by Olli Miettinen, an epidemiologist at McGill University in Montreal, argue that the Cochrane review misses this evidence by insisting that overall mortality is the only measure of its effectiveness. They argue that this approach obscures the small, but nonetheless real, benefits of the procedure. "To come to the conclusion that there is no benefit is wrong," says team member Claudia Henschke, a radiologist at Weill Medical College in New York.

Most of the evidence that mammograms save lives by catching cancer early comes from studies conducted in the 1970s and 1980s involving almost half a million women in four countries. Five of the studies concluded that regular screening reduces breast cancer deaths by an average of 30\%; two other studies found no benefit.

One reason for the difficulty in settling the disagreement is that the health effects being measured are so small, says William

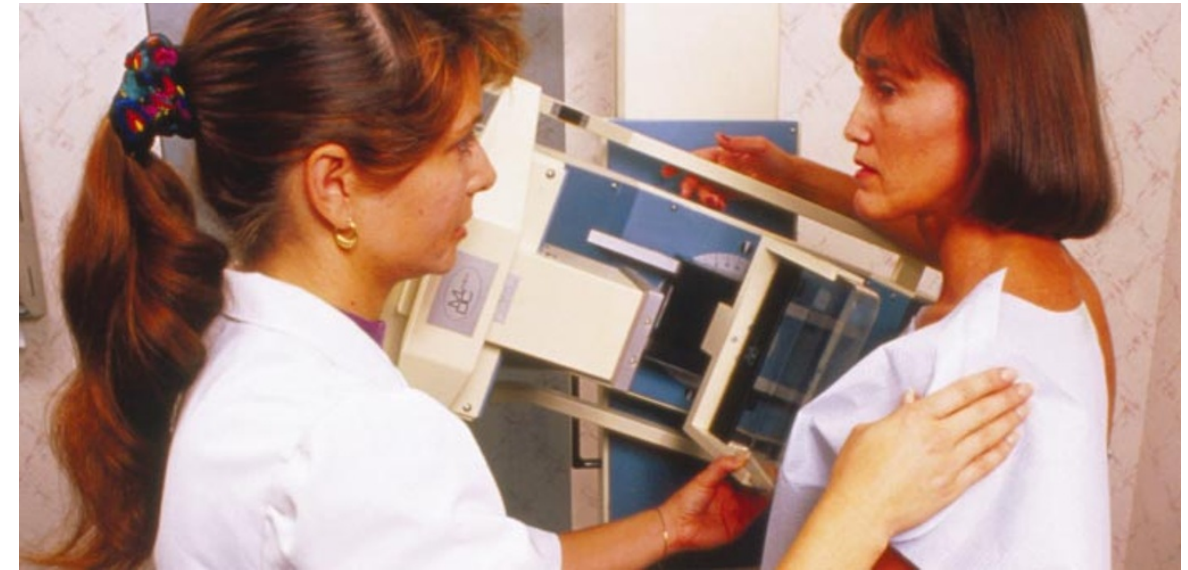

Fresh assessments have cast doubt on data suggesting that regular mammograms save lives.

Black, a radiologist at Dartmouth Medical School in New Hampshire; even slight biases in determining the cause of death are likely to throw the results off. Black and his colleagues argue in a paper published this week that such biases are rampant in randomized cancer-screening trials (see J. Natl Cancer Inst. 94, 167-173; 2002).

On 23 January, the NCI's Physician Data Query Screening and Prevention Editorial Board, an independent panel of experts set up to evaluate the literature on cancer screening for doctors and patients, agreed that the Cochrane review had raised some valid questions. "The bottom line is uncertainty," says panel member Donald Berry, a biostatistician at the University of Texas M. D. Anderson Cancer Center in Houston.

But the NCI will stick to its current screening recommendations, at least until the screening and prevention board's report is released in March, says NCI cancerprevention chief Peter Greenwald. "I'm not sure whether we would consider revising the guidelines, but we will certainly consider the board's report," he says.

\section{Climate lobby group closes down}

Virginia Gewin, Washington

The Global Climate Coalition (GCC), the main US lobby group opposed to mandatory cuts in greenhouse-gas emissions, has shut up shop.

In a statement on its website, the GCC says that, in effect, it is declaring victory and going home. With the Bush administration rejecting the Kyoto Protocol on climate change and instead backing a national strategy that relies on technology, rather than regulation, to cut greenhouse-gas emissions, the GCC claims to have achieved its main objectives.

But critics of the GCC point out that it has lost many of its best-known members including DuPont, Shell, Texaco, Ford and General Motors - in the past two years. Many of these corporations have publicly acknowledged the dangers of global warming, which the GCC played down for the 13 years of its existence.

“After a while, there weren't many leading companies left that wanted to be associated with the view the GCC was advancing," says Lester Brown, founder and former chairman of the Washington-based Worldwatch
Institute, an environmental lobby group. Eileen Claussen, president of the Pew Center on Global Climate Change, a Washington-based group that works with industrial companies that believe climate change to be a problem, says that the United States is still likely to take various actions to reduce emissions, and that the GCC's talk of victory is premature.

www.globalclimate.org

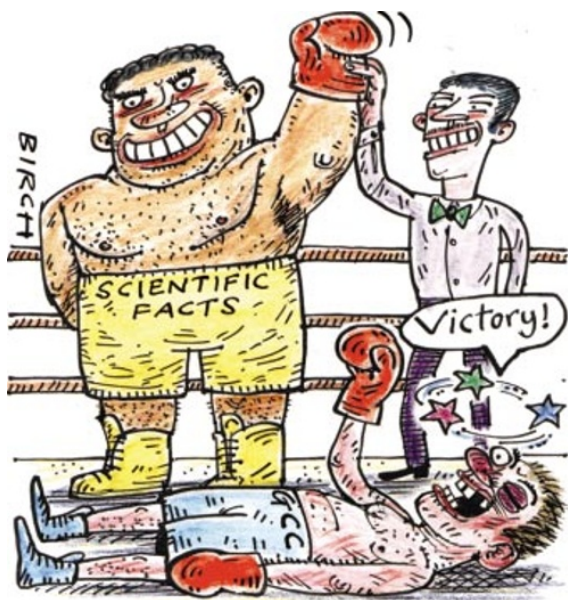

